Research Article

\title{
A Descriptive Study to Assess Attachment Styles, and Emotional Stability in Relation to Marital Satisfaction among Couples Residing in Selected Residential Areas of Gurugram, Haryana
}

\author{
Kavita Kumari', Bindu Shaiju², Asha Aniyan $^{3}$ \\ ${ }^{1}$ M. Sc. Nursing Student, Jamia Hamdard, New Delhi, India. \\ ${ }^{2}$ Associate professor, ${ }^{3}$ Tutor, Rufaida college of Nursing, Jamia Hamdard, New Delhi, India. \\ DOI: https://doi.org/10.24321/2581.5822.202007
}

I $\quad \begin{array}{lllll}\mathbf{N} & \mathbf{F} & \mathbf{O}\end{array}$

E-mail Id:

tanwar22kavita@gmail.com

Orcid Id:

https://orcid.org/0000-0003-0419-3420

How to cite this article:

Kumari K, Shaiju B, Aniyan A. A Descriptive Study to Assess Attachment Styles, and Emotional Stability in Relation to Marital Satisfaction among Couples Residing in Selected Residential Areas of Gurugram, Haryana. J Adv Res Psychol Psychother 2020; 3(3\&4): 1-7.

Date of Submission: 2020-06-13

Date of Acceptance: 2020-12-12
$\begin{array}{lllllllllll}\mathbf{A} & \mathbf{B} & \mathbf{S} & \mathbf{T} & \mathbf{R} & \mathbf{A} & \mathbf{C} & \mathbf{T}\end{array}$

Background: Marriage is one of the main decisions that an individual make in their life. Marital satisfaction constitutes the main determinant of life. There are several factors which predict marital satisfaction among couple like their attachment styles, emotional stability and demographic variables.

Objective: To assess attachment styles, emotional stability of married couples, to seek relationship between marital satisfaction with their attachment styles and emotional stability and to seek relationship of marital satisfaction with selected demographic variables.

Material and Method: A descriptive research design including 50 married couples via purposive sampling. Tools used were- For Attachment styles-Adult attachment scale, For marital satisfaction-ENRICH marital satisfaction scale, For emotional stability-Schutte Self Report Emotional Intelligence Test . Analysis and interpretation was done through SPSS version 16.0 .

Result: The findings revealed that out of 50 subjects, maximum $80 \%$ had Secure attachment style, maximum $100 \%$ male and $98 \%$ females were emotionally stable and maximum $96 \%$ males and $94 \%$ females had moderate marital satisfaction.

All attachment styles and emotional stability had non significant positive relationship with marital satisfaction. Regarding demographic variables all had non significant relationship with marital satisfaction except age and family income.

Conclusion: The study concluded that majority of married couples had moderate marital satisfaction and attachment style and emotional stability are predictors of marital satisfaction among married couples.

Keywords: Marital Satisfaction, Emotional Stability, Attachment Styles and Married Couples 


\section{Introduction}

Marital relation is the relationship between wife and husband. A healthy marital relationship is where there is communication, in which husband and wife both discuss almost everything with each other before taking any decision. They also communicate about their problems, their emotions, their needs and desires. ${ }^{1}$ One of the factors that is related to, and can affect marital satisfaction is the demographic factor which focuses on the couple's education, marriage age, age difference, marriage duration, working women and men, the existence and number of children, the spouse's economic situation, and cross-cultural marriage. $^{2}$

Adults feel comforted when their attachments are present and anxious or lonely when they are absent. Romantic or platonic partners desire to be close to one another. Securely attached people tend to have positive views of their relationships. Often they report greater satisfaction and adjustment in their relationships than people with other attachment styles. Securely attached people feel comfortable both with intimacy and independence. ${ }^{3}$

Kaslow FW., (2002) believes that the couples who have a strong sense of belonging are more acquired with marital satisfaction. He comes to this conclusion in his studies that the highest amount of marital satisfaction is among the spouses who are compatible with each other concerning philosophy of life, their perceptions of sexual satisfaction, the amount of time they spent with each other and how they spend leisure time with each other. Some studies showed that components such as level of cooperation, emotional reactions, family relationships financial issues management, sexual relationship, how to spend leisure time, ethical and religious beliefs and doing them practically, social customs and traditions, emotional satisfying, cognitive and intellectual understanding, level of education and beauty are among the factors affecting marital stability and satisfaction. Taking these factors into consideration, marital satisfaction and dissatisfaction dimensions are identified and categorized by experts in various areas. The emotional stability or instability, as a feature in the range of characteristics, can make clear an important field of the issues related to family relationships in the form of interpersonal relationships; an issue that has less been researched. Emotional intelligence includes: emotional development, being emotionally stable, being calm and realistic in life, lack of nervous exhaustion and having comfort. The research shows that some strains of negative emotion such as impulsivity, emotional instability, being fearful and depressed are poor predictors of marital adjustment. ${ }^{4}$

\section{Material and Methods}

Study place and study duration: The present study is conducted in selected residential area (Rosewood city) in Gurugram Haryana.

Study duration: The study was conducted for a period of 1 month in month of September in year 2019.

Study design: To observe, describe, and document affect of attachment styles and emotional stability on marital satisfaction among couples descriptive design is used in this study.

Sampling and sampling technique: Purposive sampling was used to select 100 married couples from selected residential areas of Gurugram Haryana.

\section{Ethical Consideration}

- Ethical consent was taken from Jamia Hamdard Institutinal Ethics Committee (JHIEC), Hamdard Nagar, New Delhi; to conduct the research study.

- Written informed consent was taken from each study subjects. They were assured of anonymity and confidentiality of information provided during the study. The consent also gave the right to withdraw from the study at any time.

- Also, coding of the participant's name was done which ensured their anonymity.

\section{Reliability of the Tool}

Tool 1: Collins and Read (1990) reported Cronbach's alpha coefficient of 0.69 for close, 0.75 for Depend, and 0.72 for Anxiety. Test- retest correlations for a 2 month period were 0.68 for Close, 0,71 for Depend and 0.52 for Anxiety ( Average correlation is 0.08). (Blaine J. Fowers, David H. Olson 1989).

Tool 2: By using Pearson product moment coefficient of correlation, the internal consistency of marital satisfaction scale was 0.696 ncronbach alpha level.

Tool 3: Reliability rating of 0.90 for their emotional intelligence scale has been calculated.

\section{Eligibility Criteria}

Inclusion Criteria: A) Married couple married for more than 2 years and residing in selected residential areas of Gurugram Haryana. B) Married couples who are coinhabiting. C) Married couples having 1-3 children. D) Married couple who are willing to participate in the study. E) Married couple who can read and write English language. F) Married couple of age $18-40$ years

Exclusion Criteria: A)Married couples among whom either husband or wife is remarried.

\section{Study Tool}

The structured questionnaire was divided into 4 parts to assess emotional stability, marital satisfaction and emotional stability among married couples. 
Part 1: Consists of structured questions related to demographic data of the married couple such as age, educational status, socio-economic status, type of marriage, duration of marriage and number of children.

Part 2: Consists of standardized tool for assessing attachment style of married couple. Adult Attachment Scale (AAS).

The scale consists of 18 items scored on a 5 point likert-type scale. It measures adult attachment style named "Secure", "Anxious" and "Avoidant", defined as:

- Secure=high scores on Close and Depend subscales, low score on Anxiety subscale

- Anxious=high score on Anxiety subscale, moderate scores on Close and Depend subscales

- Avoidant=low scores on Close, Depend, and Anxiety subscales

Part 3: Consists of standardized tool for assessing Marital Satisfaction- ENRICH Marital Satisfaction Scale (EMS). The EMS is 15 item scale comprising the idealistic distortion (5 items) and marital satisfaction scale (10 items). The positive and negative signs to the left of each item indicate whether the item should be scored in a positive or negative direction. Items scored in a negative direction would be reversed scored ( i.e., if it is marked 5 , it would be scored 1 ; if it is marked 4, it would scored 2; a 3 remains unchanged) . Categories A)15-35-Low satisfaction. B) 36-47- Moderate satisfaction. C) 55-75- High satisfaction.

Part 4: A tool to assess emotional stability - Schutte Self Report Emotional Intelligence Test ( SSEIT). It is a method of measuring general emotional intelligence using 4 subscales: Emotion perception, utilizing emotions, managing selfrelevant emotions, and managing other's emotions.

The SSEIT includes a 33-items self-report using a 1 (strongly agree) to 5 (strongly disagree) scale for responses. Each subtest score is graded and then added together to give the total scorefor the participants. Categories: A) 7-108-Emotionally unstable B) 109-217- Emotionally stable.

\section{Data Entry and Analysis}

Both descriptive and inferential statistics was used for data analysis. Background variables were expressed in terms of frequency and percentage. Attachment styles among married couples were expressed as mean, mean difference, standard deviation and t-test. Emotional stability among married couples were expressed as mean difference, standard deviation and t-test. Relationship of marital satisfaction between couples with attachment style and marital satisfaction were expressed as Coefficient of correlation.Relationship of marital satisfaction between couples with selected demographic variables - Age among couples, Education status, marriage duration, socio economic status, type of marriage was expressed as Chi-square test.

\section{Result}

\section{Frequency and Percentage Distribution of Married Couples (Gender Wise) According to their Age, Educational Status, Family Income, Marriage type, Number of Children and Family Structure}

For the present study 100 married couples are taken. 10 (20\%) males and 19 (38\%) females out of 50 married couple were in age group of $18-29$ years and $40(80 \%)$ males and 31 (62\%) females were in age group of $30-40$ years.In terms of educational status, none had studied up to secondary school and senior secondary school, $4(8 \%)$ male subjects and $6(12 \%)$ female subjects studied up to Diploma, 24 (48\%) male subjects and 24 (48\%) female subjects had graduation, 22 (44\%) male subjects and 20 (40\%) female subjects had post graduation. Regarding family income, 5 (10\%) couples had monthly income of Rs.30,000-40,000, 13 (26\%) couples had monthly income of Rs.40,001-50,000, 18 (36\%) couples had monthly income of Rs.50,001-1lakh and 14 (28\%) couples had monthly income of above 1 lakh. Further the data revealed that 20 (40\%) couples had love marriage and 30 (60\%) had arranged marriage. Regarding number of children, 21 (42\%) couples had 1 child, 23 (46\%) had 2 children, $6(12 \%)$ had 3 children and none had 4 children. With regard to family structure, 31 (62\%) couples were in nuclear family, 19 (38\%) were in joint family and none were in extended family.

Table I.Distribution of married couples (gender wise) as per their attachment styles and emotional stability in terms of their frequency and percentage

$n 1(50)+n 2(50)$

\begin{tabular}{|c|c|c|c|}
\hline \multirow{2}{*}{ Gender } & $\begin{array}{c}\text { Attachment } \\
\text { styles Categories }\end{array}$ & Frequency & $\begin{array}{c}\text { Percentage } \\
\text { (\%) }\end{array}$ \\
\hline \multirow{3}{*}{$\begin{array}{c}\text { Males } \\
\text { (n1=50) }\end{array}$} & Secure & 40 & 80 \\
\cline { 2 - 4 } & Anxious & 10 & 20 \\
\cline { 2 - 4 } & Avoidant & 0 & 0 \\
\hline \multirow{2}{*}{$\begin{array}{c}\text { Females } \\
\text { (n2=50) }\end{array}$} & Secure & 44 & 88 \\
\cline { 2 - 4 } & Anxious & 6 & 12 \\
\cline { 2 - 4 } & Avoidant & 0 & 0 \\
\hline
\end{tabular}

n1 (male spouse), n2 (female spouse).

Table 1, shows that Out of 50 male subjects 40 (80\%) had Secure attachment Style, 10 (20\%) had Anxious attachment Style and none had avoidant attachment styles whereas among 50 women subjects, 44 (88\%) had Secure attachment style, $6(12 \%)$ had anxious attachment style and none had avoidant attachment style.

There were more homogeneity among female than male in all three attachment styles andthere is no significant difference between males and females among married couples in terms of their secure attachment style whereas 
there is significant difference between males and females among married couples in terms of their anxious and avoidant attachment styles.

Table 2, reveals that all male subjects $50(100 \%)$ were emotionally stable and none were emotionally unstable, whereas almost all female subject $49(98 \%)$ were emotionally stable and only $1(2 \%)$ out of 50 females were emotionally unstable among married couples.

Females were more homogenous than males and there is no significant difference between males and females among married couples in terms of their emotional stability.

Table 3, shows that out of 50 male subjects had low marital satisfaction, 48 (96\%) had moderate marital satisfaction and none had high marital satisfaction. Whereas, among 50 female subjects, 2 (4\%) subjects had low marital satisfaction, $47(94 \%)$ had moderate marital satisfaction and $1(2 \%)$ had high marital satisfaction.

Secure and anxious attachment style among male and female spouse had statically non- significant and positive correlation with marital satisfaction and Avoidant attachment style among male and spouse had statically significant and positive correlation with marital satisfaction whereas avoidant attachment style among female spouse had statically non-significant and positive.

Table 2.Frequency and percentage distribution of married couples (gender wise) as per their emotional stability $\mathrm{n} 1(50)+\mathrm{n} 2(50)$

\begin{tabular}{|c|c|c|c|}
\hline Gender & Categories of emotional stability & Frequency & Percentage (\%) \\
\hline \multirow{2}{*}{ Males (n1=50) } & Emotionally Stable & 50 & 100 \\
\cline { 2 - 4 } & Emotionally Not stable & 0 & 0 \\
\hline \multirow{2}{*}{ Female (n2=50) } & Emotionally Stable & 49 & 98 \\
\cline { 2 - 4 } & Emotionally Not stable & 1 & 2 \\
\hline
\end{tabular}

n1(male spouse), n2(female spouse)

Table 3.Distribution of married couples (Gender wise) in terms of Frequency and Percentage of their marital Satisfaction

\begin{tabular}{|c|c|c|c|}
\hline \multicolumn{1}{|c|}{$\mathrm{n} 1(50)+\mathrm{n} 2(50)$} \\
\hline \multirow{3}{*}{ Gender } & Categories of marital satisfaction & Frequency & Percentage (\%) \\
\cline { 2 - 4 } & Low satisfaction & 2 & 4 \\
\cline { 2 - 4 } & Moderate satisfaction & 48 & 96 \\
\hline \multirow{3}{*}{ Female } & High satisfaction & 0 & 0 \\
\cline { 2 - 4 } & Low satisfaction & 2 & 4 \\
\cline { 2 - 4 } & Moderate satisfaction & 47 & 2 \\
\hline
\end{tabular}

n1(male spouse), n2(female spouse)n3=100=(married couples with $50 \mathrm{n} 1$ and $50 \mathrm{n} 2$ ).

Table 4.Distribution of married couples showing relationship between marital satisfaction with their attachment styles and emotional stability

\begin{tabular}{|c|c|c|c|c|c|c|}
\hline Variable & $\begin{array}{c}\text { Mean of } \\
\text { variable } \\
\text { score }\end{array}$ & $\begin{array}{c}\text { Mean of } \\
\text { marital } \\
\text { satisfaction }\end{array}$ & $\begin{array}{c}\text { Standard } \\
\text { deviation of } \\
\text { variable score }\end{array}$ & $\begin{array}{c}\text { Standard deviation } \\
\text { of marital } \\
\text { satisfaction }\end{array}$ & 'r value' & P-value \\
\hline Secure attachment (M) & 19.7 & 41.24 & 3.660322 & 3.419989 & 1.00 & 0.5 \\
\hline Anxious attachment (M) & 20 & 41.24 & 3.103652 & 3.419989 & 1.00 & 0.5 \\
\hline Avoidant attachment (M) & 18.66 & 41.24 & 3.40234 & 3.419989 & 0.99 & $0.00 *$ \\
\hline Secure attachment (F) & 19.44 & 42.74 & 3.246097 & 4.165162 & 1.00 & 0.5 \\
\hline Anxious attachment (F) & 18.3 & 42.74 & 2.242903 & 4.165162 & 1.00 & 0.5 \\
\hline Avoidant attachment (F) & 17.16 & 42.74 & 3.908964 & 4.165162 & 1.00 & 0.5 \\
\hline Emotional stability (M) & 172.36 & 41.24 & 16.94139 & 3.419989 & 1.00 & 0.5 \\
\hline Emotional stability (F) & 169.62 & 42.72 & 15.62297 & 4.165162 & 1.00 & 0.5 \\
\hline
\end{tabular}

$\mathrm{M}=$ Male spouse, $\mathrm{F}=$ Female spouse. 
Emotional stability among male and female spouse had significant and positive correlation with marital satisfaction.

Table 4, shows that secure and anxious attachment style among male and female spouse had statically nonsignificant and positive correlation with marital satisfaction and Avoidant attachment style among male and spouse had statically significant and positive correlation with marital satisfaction whereas avoidant attachment style among female spouse had statically non-significant and positive. Emotional stability among male and female spouse had significant and positive correlation with marital satisfaction.

Table 5.Distribution of married couples seeking relationship marital satisfaction with selected demographic variables - Age difference among couples, Education status, marriage duration, socio economic status, type of marriage

$n 1(50)+n 2(50)$

\begin{tabular}{|c|c|c|c|c|c|c|}
\hline \multirow{2}{*}{ Gender } & \multirow{2}{*}{ variables } & \multicolumn{2}{|c|}{ Marital satisfaction } & \multirow{2}{*}{ df } & \multirow{2}{*}{$\begin{array}{l}\text { Chi- square value (with } \\
\text { Yates correction) }\end{array}$} & \multirow{2}{*}{$p$-value } \\
\hline & & Low & Moderate & & & \\
\hline \multicolumn{7}{|l|}{ Males } \\
\hline & Age & & & & & \\
\hline & $18-29$ & 2 & 8 & 1 & 3.94 & 0.0472 \\
\hline & $30-40$ & 0 & 40 & & & \\
\hline & Educational status & & & & & \\
\hline & Diploma & 1 & 3 & 2 & 5.61 & 0.0605 \\
\hline & Graduation & 0 & 24 & & & \\
\hline & Post Graduate & 1 & 21 & & & \\
\hline & $\begin{array}{c}\text { Family income } \\
\text { (Monthly) }\end{array}$ & & & & & \\
\hline & $30,000-40,000$ & 2 & 3 & 3 & 18.75 & $0.0003^{*}$ \\
\hline & $40,001-50,000$ & 0 & 13 & & & \\
\hline & 50,001-1 lakh & 0 & 18 & & & \\
\hline & Above 1 lakh & 0 & 14 & & & \\
\hline & Marriage type & & & & & \\
\hline & Love marriage & & 1 & 1 & 0.2 & 0.6547 \\
\hline & Arrange marriage & & 1 & & & \\
\hline & No of children & & & & & \\
\hline & 1 & 2 & 20 & & & \\
\hline & 2 & 0 & 23 & 2 & 2.65 & 0.2658 \\
\hline & 3 & 0 & 5 & & & \\
\hline & Family structure & & & & & \\
\hline & Nuclear & 1 & 30 & 1 & 0.02 & 0.8875 \\
\hline & Joint & 0 & 19 & & & \\
\hline
\end{tabular}

\begin{tabular}{|l|c|c|c|c|c|c|c|c|}
\hline \multirow{2}{*}{} & \multirow{2}{*}{ variables } & \multicolumn{3}{|c|}{ Marital satisfaction } & \multirow{2}{*}{ df } & \multicolumn{2}{c|}{$\begin{array}{c}\text { Chi-square (with Yates } \\
\text { correction }\end{array}$} & P-value \\
\cline { 3 - 7 } & Low & Moderate & High & & & & \\
\hline Females & Age & & & & & & 0.6907 \\
\hline & $18-29$ & 1 & 18 & 0 & 2 & 0.72 & \\
\hline
\end{tabular}




\begin{tabular}{|c|c|c|c|c|c|c|}
\hline Educational status & & & & & & \\
\hline Diploma & 1 & 5 & 0 & 4 & 4.79 & 0.3095 \\
\hline Graduation & 1 & 23 & 0 & & & \\
\hline Post Graduate & 0 & 19 & 1 & & & \\
\hline $\begin{array}{l}\text { Family income } \\
\text { (Monthly) }\end{array}$ & & & & & & \\
\hline $30,000-40,000$ & 2 & 3 & 0 & 6 & 21.53 & 0.0015 \\
\hline $40,001-50,000$ & 0 & 13 & 0 & & & \\
\hline 50,001-1 lakh & 0 & 18 & 0 & & & \\
\hline Above 1 lakh & 0 & 14 & 1 & & & \\
\hline Marriage type & & & & & & \\
\hline Love marriage & 1 & 19 & 0 & 2 & 0.75 & 0.6873 \\
\hline Arrange marriage & 1 & 28 & 1 & & & \\
\hline No of children & & & & & & \\
\hline 1 & 2 & 20 & 0 & & & \\
\hline 2 & 0 & 22 & 1 & 4 & 3.77 & 0.438 \\
\hline 3 & 0 & 5 & 0 & & & \\
\hline Family structure & & & & & & \\
\hline Nuclear & 1 & 30 & 0 & 2 & 1.82 & 0.4025 \\
\hline Joint & 1 & 17 & 1 & & & \\
\hline
\end{tabular}

Table 5, shows that there is no significant relationship between marital satisfaction and educational status, marriage type, number of children, family structure among both husband and wives among married couples and there is significant relationship between marital satisfaction and family income of both husband and wives among married couples. The only difference is that age and marital satisfaction among husband have significant but wives have no significant relationship.

\section{Discussion}

Marital satisfaction is a mental state that reflects the perceived benefits and costs of marriage to a particular person. The more costs a marriage partner inflicts on a person, the less satisfied one generally is with the marriage and with the marriage partner. A good marriage provides individuals with a sense of meaning and identity in their lives. Attachment styles and emotional stability play in important role in determining marital satisfaction among married couples.

The present study revealed that there is no significant difference is found between males and their female's counterparts in terms of attachment styles and emotional stability which was consistent with the study findings of Hamid. F, who conducted a study to determine the relationship between attachment styles and marital satisfaction in married students of Teacher training university.62 married students (33 females) from human science faculty were selected through disposal sampling. The study concluded that no significant difference was found between males and female students in marital satisfaction; finally there was no significant difference between male and female students in attachment styles. ${ }^{5}$

The study also revealed that all three attachment styles (Secure, Anxious and avoidant ) had significant positive relationship with marital satisfaction, hence, attachment style can significantly predict marital satisfaction. Emotional stability had significant positive correlation with marital satisfaction and can therefore significantly predict marital satisfaction which is consistent with the study finding of Tummalaarruna, who conducted study to assess attachment styles and emotional stability in married couples. The study concluded there is significant positive correlation between attachment styles and emotional stability to marital satisfaction among married couples. ${ }^{6}$

Present study revealed that age and family income had significant role in marital satisfaction among married couples, However, study conducted by Farzaneh in Iran on 50 married couples to investigate the effective factors in marital satisfaction and concluded that one of the factor that is related to, and can effect marital satisfaction is demographic factors which focuses on the couple's education, age, age difference, marital duration, working 
women and men, the existence of number of children, the spouse economic situation and cross-cultural marriages. ${ }^{7}$

\section{Conclusion}

The objectives of the present study were achieved as the three attachment styles (Secure, anxious and avoidant) are assessed. There is no significant difference between males and females among married couples in terms of their secure attachment style whereas there is significant difference between males and females among married couples in terms of their anxious and avoidant attachment styles.

Emotional stability of the married couples were assessed. Almost all male couples were emotionally stable and none were emotionally unstable

Correlation of marital satisfaction with attachment styles and emotional stability is assessed. All attachment styles (Secure, Anxious and avoidant) had significant positive relationship with marital satisfaction, hence, attachment style can significantly predict marital satisfaction. Emotional stability had significant positive correlation with marital satisfaction and can therefore significantly predict marital satisfaction of both husband and wives. It revels emotionally stable couples are more satisfied with their marriage.

Correlation of marital satisfaction with demographic variables is assessed. There is no significant relationship between marital satisfaction and educational status, marriage type, number of children, family structure among both husband and wives among married couples and there is significant relationship between marital satisfaction and family income of both husband and wives among married couples. The only difference is that age and marital satisfaction among husband have significant but wives have non significant relationship.

The study have implications in nursing services, nursing Education and Nursing administration where nurses should be well equipped with knowledge about attachment styles, emotional stability and their relationship with marital satisfaction so nurses can able to deal effectively with couples and their problems in community and is able to counsel them effectively. Student nurses may be provided with learning experiences for the use of attachment styles, emotional stability and marital satisfaction scale on couples in need in their family, community, among their couples and among themselves and their spouses (If they are married), Identify their problems and resolve them. The nurse educator must ensure that the psychological, emotional needs of the couples must be considered and met through frequent counselling sessions by the nurses in community and health care setting and She/ He should provide adequate support and funds to in-service education for nurses working in these areas and educational sessions to client on various aspects of marital conflicts.
Limitations of the present study was the sample size was small and limited to only selected residential areas of Gurugram. So generalization could not be made and obtaining the desired sample within limited period was a little difficult for the researcher.

\section{Conflict of Interest: None}

\section{References}

1. Jcarroll, THolman Knapps. Theorizing about marriage in Bengston, et a sourcebook of family theory and research, Thousand oaks, A sag, 2005; 263-277.

2. Rezaeanlangroodi R, Azizinazahad M, Hashemi M. The investigation of biological and psychological of marriage criteria from the view points of Iranian University students with that of their parents. Procediasocial and behavioral sciences 2011; 28: 40-10. DOI: 10.1016/j. sbspro.2011.11.077. 3.

3. Hamidi F. A study on the relationship between attachment styles and marital satisfaction in married students of teacher training university. J Fam Res 2007; 3(9): 443-453.

4. Kaslow FW. Portrayal of the Healthy Couple. Psychiatric Clinic of of North America 2002; 5(7); 519-527.

5. Hamid F. The relationship between attachment styles with marital satisfaction among nurses. Journal of family research 2007; 443-453.

6. Tummala A. The Relationship Between Attachment Styles and Lifestyle With Marital Satisfaction. Iran Red Crescent Med J 2016; 18(4): e23839. DOI: 10.5812/ ircmj.23839.

7. Farzaneh. Trend Analysis of Changes in Marital Satisfaction and Related Dimensions across Family Life Cycle. Journal of Family Research 2010: 6(21): 5-22. 